\title{
Effect of sigma phase precipitation on microstructure and properties of cast ZG0Cr26Ni5Mo3Cu3 duplex stainless steel under different heat treatments
}

\author{
Ze-hua Zhu ${ }^{1,2}$, Wei-dong Zhang ${ }^{3}$, ${ }^{*}$ Xiao-hui Tu ${ }^{1,2}$, Xiao-jian Wang ${ }^{1,2}$ and Wei Li ${ }^{1,2}$ \\ 1. Institute of Advanced Wear \& Corrosion Resistant and Functional Materials, Jinan University, Guangzhou 510632, China, \\ 2. National Joint Engineering Research Center of High Performance Metal Wear Resistant Materials Technology, Jinan University, Guangzhou \\ 510632, China; \\ 3. Zhongshan Guangzhong Foundry \& Rolling Co., Ltd., Zhongshan 528429, China
}

\begin{abstract}
ZG0Cr26Ni5Mo3Cu3 Duplex Stainless Steel (DSS) was solution treated at $1,060{ }^{\circ} \mathrm{C}$ for $3 \mathrm{~h}$, followed by water cooling. Tempering treatments were conducted at 720,750 and $780{ }^{\circ} \mathrm{C}$, respectively, for $16 \mathrm{~h}$, followed by air cooling. The microstructures of ZG0Cr26Ni5Mo3Cu3 duplex stainless steel samples treated at different tempering temperatures were observed by scanning electron microscope (SEM) and energy dispersal spectroscopy (EDS), and the phase consitutions were analyzed using X-ray diffraction (XRD). The effects of the precipitation of sigma $(\sigma)$ phase on the duplex phase percentage, hardness, impact toughness and corrosion resistance of the DSS were studied. Results showed that microstructures of ZG0Cr26Ni5Mo3Cu3 after solution treatment consists of ferrite $(\alpha)$ phase and austenite $(\gamma)$ phase; after being tempered at different temperatures, $\sigma$ phase appeared due to a eutectoid-type reaction of $\alpha \rightarrow \sigma+\gamma_{2}$ during tempering treatment. It was observed that $\sigma$ phase distributed along the grain boundary. The volume fraction of $\sigma$ and $y$ phases increased with increasing tempering temperature in the range of 720 to $780{ }^{\circ} \mathrm{C}$, whereas the volume fraction of a phase showed the opposite trend. When the percentage of $\sigma$ phase increased, the hardness of steel also increased. In the solution treated steel, hardness was measured to be only $244.0 \mathrm{HB}$, because $\sigma$ phase did not appear. However, it increased to $391.8 \mathrm{HB}$ when the DSS was tempered at $780^{\circ} \mathrm{C}$ because a great of deal of $\sigma$ phase appeared. The impact toughness and corrosion resistance of DSS decreased when the percentage of $\sigma$ phase increased.
\end{abstract}

Key words: Duplex stainless steel; tempering; sigma phase; hardness; impact toughness; corrosion resistance
CLC numbers: TG142.1
Document code: $\mathrm{A}$
Article ID: 1672-6421(2018)03-182-07

$\mathrm{D}$ uplex Stainless Steels (DSSs), consist of austenite $(\gamma)$ phase and ferrite $(\alpha)$ phase, in which each phase should reach to at least $30 \%{ }^{[1]}$. The $\gamma$ and $\alpha$ phase percentage in DSSs can be changed by the content of chemical elements and by the heat treatment process ${ }^{[2-3]}$. DSSs combine the advantages of both ferritic and austenitic stainless steels which exhibit excellent mechanical properties, good weldability and high corrosion resistance ${ }^{[4-7]}$. Therefore, they are used in

\section{*Xiao-hui Tu}

Male, born in 1964, Professor. His research interests mainly focus on wearand corrosion-resistant metal materials.

E-mail: 3162510484@qq.com

Received: 2017-11-05; Accepted: 2018-03-25 chemical, energy, petrochemical, marine, mining, power generation, food, nuclear, agriculture, oil, and paper industries ${ }^{[8-11]}$.

The alloy compositions of DSSs contain higher $\mathrm{Cr}$, Mo and $\mathrm{N}$ than that of normal stainless steels. It is easy to precipitate $\sigma$ phase (an $\mathrm{Fe}-\mathrm{Cr}-\mathrm{Mo}$ intermetallic phase, quartet structure), $\chi$ phase $\left(\mathrm{Fe}_{36} \mathrm{Cr}_{12} \mathrm{Mo}_{10}\right.$, cubic structure), $\pi$ phase $\left(\mathrm{Fe}_{7} \mathrm{Mo}_{13} \mathrm{~N}_{4}\right.$, cubic structure) or intermetallic compounds such as $\mathrm{CrN}, \mathrm{Cr}_{2} \mathrm{~N}$ and $\mathrm{M}_{23} \mathrm{C}_{6}$ with a temperature of heat treatment in the range of $300-1,000{ }^{\circ} \mathrm{C}^{[12-16]}$. These precipitates have significant effects on the mechanical properties and corrosion resistance of the DSSs. The $\sigma$ phase is precipitated at the fastest speed and with the largest amount compared to $\chi$ phase, $\pi$ phase and other intermetallic compounds. It is 
a high hardness, brittle and non-magnetic phase. So, the $\sigma$ phase can reduce the impact toughness and increase the hardness. Since $\sigma$ phase is rich in $\mathrm{Cr}$ and $\mathrm{Mo}$, the adjacent zones become depleted of $\mathrm{Cr}$ and $\mathrm{Mo}$, which results in reduced corrosion resistance ${ }^{[17]}$. Study showed that the $\sigma$ phase formed after aging at temperatures between 650 and $950{ }^{\circ} \mathrm{C}$ by a eutectoid-type reaction of $\alpha \rightarrow \sigma+\gamma_{2}{ }^{[18]}$. The sigma phase usually forms at the grain boundary of the ferrite-austenite phases and inside $\alpha$ phase which has a tetragonal symmetry point group with 30 atoms per unit cell. However, its transformation mechanism is still controversial. Wang ${ }^{[19]}$ have studied the effect of $\sigma$ phase on the mechanical properties and wear resistance of $\mathrm{Z3CN} 20.09 \mathrm{M}$ cast duplex stainless steel. The results showed that the $\sigma$ phase precipitated from ferrite in a temperature range of $600-900{ }^{\circ} \mathrm{C}$. With increasing aging time, the impact energy of specimens decreased slightly before $4 \mathrm{~h}$, and then dropped drastically when being aged for a time of more than $10 \mathrm{~h}$. Lee ${ }^{[20]}$ studied the effect of the aging time on the microstructure and corrosion behavior of the weldment of $24 \mathrm{Cr}-3.5 \mathrm{Mo}$ duplex stainless steel. The results showed that the fraction of $\delta$ ferrite decreased sharply as the aging time increased, but the fraction of $\gamma$ austenite slightly increased. The $\sigma$ phase was generated in the form of a nonmetallic inclusion along the grain boundaries of $\delta$ ferrite and $\gamma$ austenite. As the intermetallic compounds increased, the critical pitting potential fell sharply.

However, studies on the ZG0Cr26Ni5Mo3Cu3 casting duplex stainless steel are not sufficient to date, especially, the effect of tempering temperature at $720-780{ }^{\circ} \mathrm{C}$ on the morphology of $\sigma$ phase precipitation, hardness, impact toughness and corrosion resistance is rarely reported. So, it is important to study the microstructure and properties of ZG0Cr26Ni5Mo3Cu3 duplex stainless steel at different tempering treatment temperatures.

\section{Experimental procedure}

The experimental raw materials in the present study were ferrochrome, metal manganese, pure nickel and copper. These materials were melted in a medium-frequency induction furnace. Molten liquid was poured into a sand mold, and the Y-blocks were obtained. The chemical composition of the tested duplex stainless steel ZG0Cr26Ni5Mo3Cu3 samples is listed in Table 1.

The equilibrium phase diagram of duplex stainless steel ZG0Cr26Ni5Mo3Cu3 between 500 and $1,600{ }^{\circ} \mathrm{C}$ was calculated using Thermocalc software. Heat treatment procedure of samples is shown in Table 2. Solution treatment of four samples marked as $\# 0, \# 1, \# 2$, and \#3 was conducted in an electric resistance furnace at $1,060{ }^{\circ} \mathrm{C}$ for $3 \mathrm{~h}$, followed by water cooling. After the solution heat treatment, samples \#1, \#2, and
Table 2: Heat treatment procedure

\begin{tabular}{c:c:c} 
Sample No. & Solution treatment & $\begin{array}{c}\text { Tempering } \\
\text { treatment }\end{array}$ \\
\hline$\# 0$ & & No tempering \\
\hline$\# 1$ & & $720^{\circ} \mathrm{C}$ for $16 \mathrm{~h}$ \\
\hline$\# 2$ & $1,060^{\circ} \mathrm{C}$ for $3 \mathrm{~h}$ & $750^{\circ} \mathrm{C}$ for $16 \mathrm{~h}$ \\
\hline$\# 3$ & & $780^{\circ} \mathrm{C}$ for $16 \mathrm{~h}$
\end{tabular}

\#3 were tempered at 720,750 and $780{ }^{\circ} \mathrm{C}$, respectively, for 16 $\mathrm{h}$ and then air cooled. Samples were cut from Y-blocks using DK 7750 wire cut electric discharge machine. Samples for the microstructure observation by a Leica DM2500M, were ground using silicon carbide abrasive paper to \#3000, polished by diamond paste with size of $1.0 \mu \mathrm{m}$, and then etched with the solution of potassium metabisulphide ${ }^{[21]}\left(\mathrm{K}_{2} \mathrm{~S}_{2} \mathrm{O}_{5}: \mathrm{HCl}: \mathrm{H}_{2} \mathrm{O}\right.$ $=1 \mathrm{~g}: 10 \mathrm{ml}: 50 \mathrm{ml})$. The volume fractions of the formation phases in steel were calculated by Image Pro-Plus software. The constitutes of each phase were identified by an X-ray diffraction (XRD) apparatus. The chemical compositions of each phase were analyzed by an energy dispersive spectroscopy (EDS). The hardness was measured by a HBRVU-187.5 optical hardness tester with a test load of $1,839 \mathrm{~N}$ (187 kgf) for $30 \mathrm{~s}$ with a $2.5-\mathrm{mm}$ diameter tungsten carbide ball indenter. The microhardness of $\alpha$ phase, $\gamma$ phase and $\sigma$ phase were determined by a micro-hardness tester. Impact toughness tests were performed using an instrumented impact tester, and the dimension of samples was $10 \mathrm{~mm} \times 10 \mathrm{~mm} \times 55 \mathrm{~mm}$ with a V-notch (Fig. 1). The impact fracture surfaces were observed on a scanning electron microscope (SEM). The electrochemical experiments were performed in a standard three-electrode electrochemical cell. The working electrodes were the samples, the reference electrode was a saturated calomel reference electrode (SCE), and the counter electrode was foil. Potentiodynamic polarization tests were conducted in a $3.5 \mathrm{wt} . \%$ simulated seawater at room temperature. The potential was scanned from $-2.5 \mathrm{~V}$ OC to $1.0 \mathrm{~V} \mathrm{OC}$ at the anodic direction with a scanning rate of 0.5 $\mathrm{mV} \cdot \mathrm{s}^{-1}$ before the open circuit potential reached a stable state. Tests were repeated three times for each sample to ensure the accuracy of results.

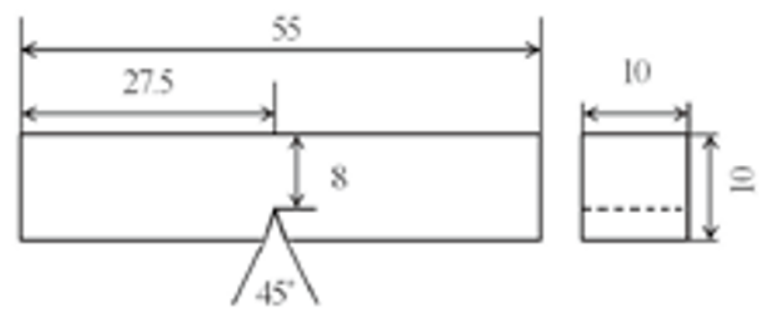

Fig. 1: Sample size for impact toughness test (unit: $\mathrm{mm}$ )

Table 1: Chemical composition of ZG0Cr26Ni5Mo3Cu3 (wt.\%)

$\begin{array}{cccccccrrrr}\mathbf{C} & \text { Si } & \text { Mn } & \text { P } & \text { S } & \text { Cr } & \text { Ni } & \text { Mo } & \text { N } \\ 0.014 & 0.31 & 0.71 & 0.032 & 0.025 & 25.66 & 5.48 & 2.71 & 0.101 & 2.80\end{array}$




\section{Results and discussion}

\subsection{Thermodynamic predictions}

Figure 2 shows the equilibrium phase diagram of the ZG0Cr26Ni5Mo3Cu3 between 500 and $1,600{ }^{\circ} \mathrm{C}$, which was calculated using Thermo-Calc software. Solidification of liquid ZG0Cr26Ni5Mo3Cu3 occurred as the temperature decreased. ZG0Cr26Ni5Mo3 Cu3 consisted of liquid and $\alpha$ phase when the temperature was $1,400{ }^{\circ} \mathrm{C}$. The content of $\gamma$ phase increased with decreasing temperature. Approximately equal amounts of $\gamma$ phase and $\alpha$ phase appeared between 950 and $1,100{ }^{\circ} \mathrm{C} . \sigma$ phase, $\mathrm{Cr}_{2} \mathrm{~N}$ and $\mathrm{M}_{23} \mathrm{C}_{6}$ precipitated below $900{ }^{\circ} \mathrm{C}$, and these precipitation phases significantly reduced the toughness of steel. The high temperature solidification mode was briefly described as follows: $\mathrm{L} \rightarrow \mathrm{L}+\alpha \rightarrow \mathrm{L}+\alpha+\gamma \rightarrow \alpha+\gamma+$ precipitates.

\subsection{Microstructural characterization}

The optical microstructures of ZG0Cr26Ni5Mo3Cu3 with different heat treatment procedures are shown in Fig. 3. Light areas in the micrograph with island-shaped, acicular-like and elongated morphologies are $\gamma$ phase, and the dark matrix is $\alpha$ phase. The bright white precipitates are $\sigma$ phase. There were plenty of $\gamma$ phase embedded inside the $\alpha$ matrix, and no other precipitates appeared when steel was only solution treated at $1,060{ }^{\circ} \mathrm{C}$ [Fig. 3(a)]. The $\sigma$ and $\gamma_{2}$ phases formed when the sample was tempered at 720,750 and $780{ }^{\circ} \mathrm{C}$ after solution treatment at $1,060^{\circ} \mathrm{C}$ [Fig. 3(b), (c), (d)]. The volume fraction and dimensions of $\sigma$ increased with increasing tempering temperature. The $\sigma$ phase only formed along the boundary of ferrite-austenite phases, when samples were tempered at 720 and $750^{\circ} \mathrm{C}$. In that case, the amount of $\sigma$ phase was less and the

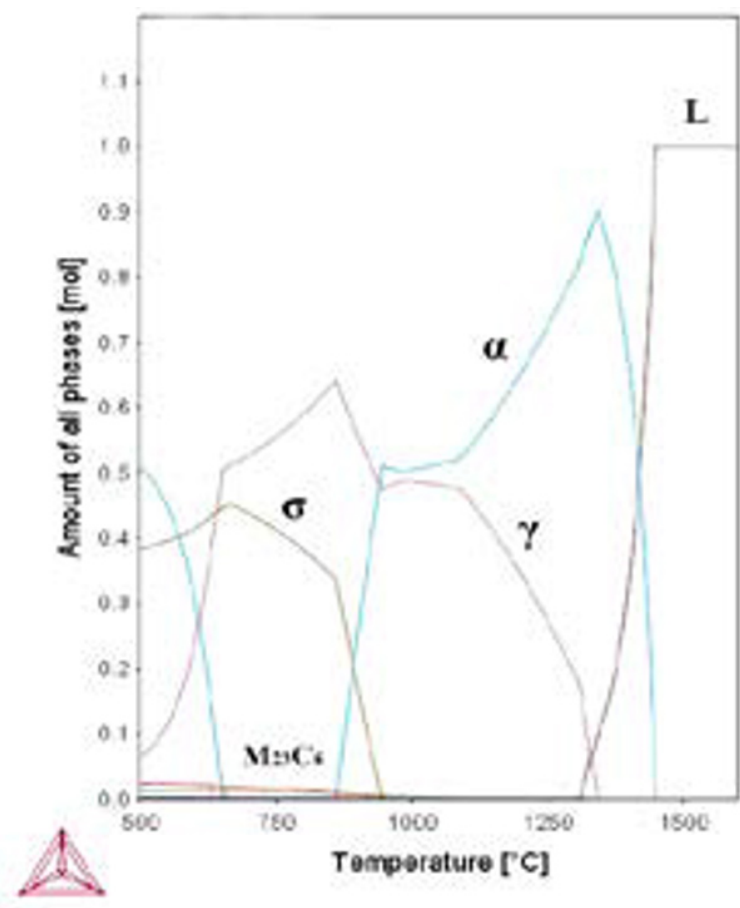

Fig. 2: Calculated equilibrium molar fractions of precipitates of ZG0Cr26Ni5Mo3Cu3 DDS

dimension was also small. However, the $\sigma$ phase formed both along the boundary of ferrite-austenite phases and inside the $\alpha$ phase, when samples were tempered at $780{ }^{\circ} \mathrm{C}$, and the volume fraction of $\sigma$ phase significantly increased and the dimension was larger than samples tempered at 720 and $750{ }^{\circ} \mathrm{C}$. When the tempering temperature was $720-780{ }^{\circ} \mathrm{C}$, the $\alpha / \gamma$ phase boundaries had a high interfacal energy, and the diffusion rate
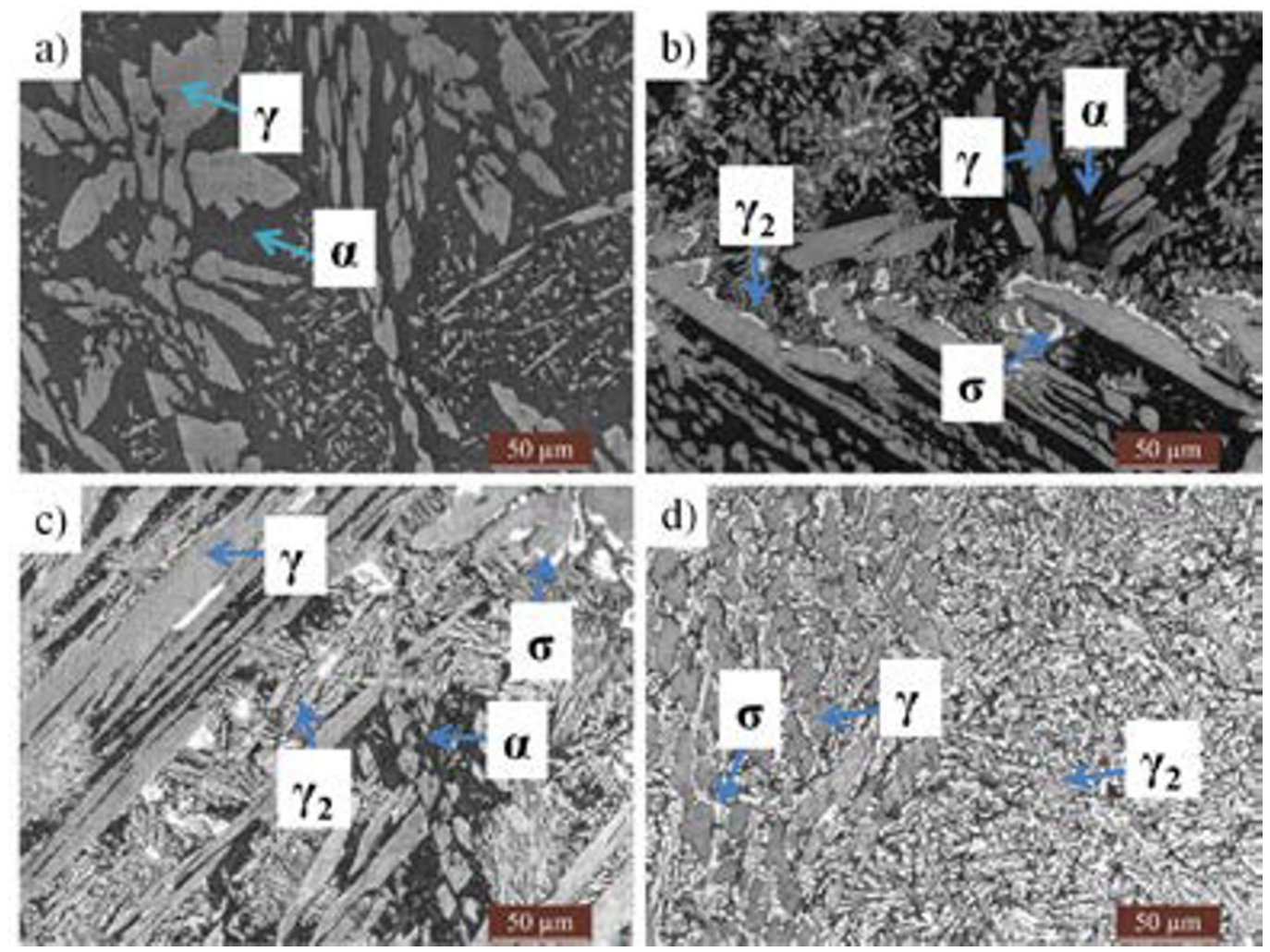

Fig. 3: Microstructure of ZG0Cr26Ni5Mo3Cu3 DDS samples: (a) \#0; (b) \#1; (c) \#2; d) \#3 
of metal elements at the grain boundary was much faster than that in the grain interior, so, $\alpha / \gamma$ phase boundary became the best location for the nucleation of $\sigma$ phase. The atom density in the ferrite lattice is lower; the diffusion rate of alloying elements in the ferrite is faster than that in the austenite. Ferrite therefore has $\mathrm{Cr}$ and Mo atoms. So, $\sigma$ phase preferentially nucleates at the ferrite-austenite phase boundaries and continuously grows into the ferrite. The $\sigma$ phase precipitates and forms $\gamma_{2}$ in the $\mathrm{Cr}$ depleted and Ni-rich regions. The $\sigma$ phase precipitation curve is C-type with a nose at about between $800-850{ }^{\circ} \mathrm{C}^{[22]}$. Tempering temperature rose from 720 to $780{ }^{\circ} \mathrm{C}$ which is close to the nose and the incubation period of $\sigma$ phase becomes shorter. Once $\sigma$ nucleated, it grew rapidly. In addition, the increase of temperature causes the increased diffusion activity of $\mathrm{Cr}$ and Mo elements in steel, and the driving force for precipitation of $\sigma$ phase increases. When the tempering temperature was raised from 720 to $780{ }^{\circ} \mathrm{C}$, the volume fraction and the dimension of $\sigma$ phase increased
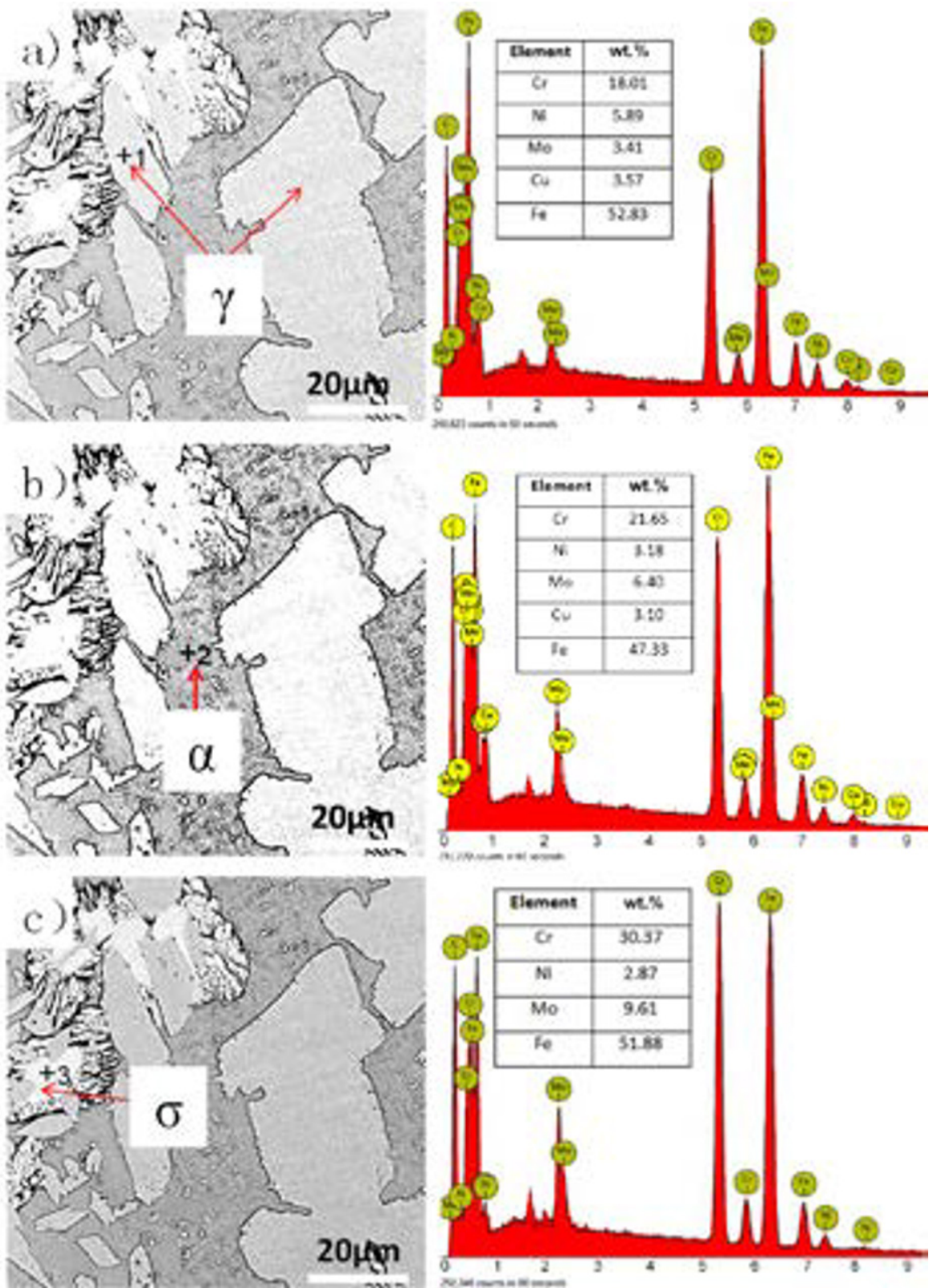

Fig. 4: SEM images and EDS results of ZG0Cr26Ni5Mo3Cu3 DDS tempered at $720^{\circ} \mathrm{C}$ after solution treatment at $1,060^{\circ} \mathrm{C}$
Figure 4 shows the EDS result of the light phase, dark phase and bright white phase in the microstructure of the sample solution treated at $1,060{ }^{\circ} \mathrm{C}$ and tempered at $720{ }^{\circ} \mathrm{C}$. The elements of $\alpha$ phase included $\mathrm{Cr}$ and $\mathrm{Mo}$, while $\mathrm{Ni}$ and $\mathrm{Cu}$ were detected in the $\gamma$ phase in DDSs. Figure 4(a) displays that the content of $\mathrm{Cr}$ and $\mathrm{Mo}$ are lower, while $\mathrm{Ni}$ and $\mathrm{Cu}$ are higher in the light phase. So the light phase is $\gamma$ phase. Figure 4(b) shows that $\mathrm{Cr}$ and $\mathrm{Mo}$ are higher, while $\mathrm{Ni}$ and $\mathrm{Cu}$ are lower in the dark phase, therefore the dark phase is $\alpha$ phase. The concentrations of $\mathrm{Cr}$ and Mo in the bright white phase [Fig. 4(c)] are significantly higher than those in Fig. 4(b), while the concentration of $\mathrm{Ni}$ in Fig. 4(c) is very low. Therefore, the bright white phase is $\sigma$ phase.

Figure 5 shows the X-ray diffraction pattern of the specimens $\# 0, \# 1, \# 2$ and \#3. The result reveals that the DDSs are mainly comprised of two phases $(\gamma$ and $\alpha$ ) without clear evidence of the precipitations of the secondary phases (such as $\sigma$ phase, $\mathrm{Cr}_{2} \mathrm{~N}$, and $\mathrm{M}_{23} \mathrm{C}_{6}$ ) when steel was only solution treated at $1,060{ }^{\circ} \mathrm{C}$.

The diffraction peak intensities of the $\gamma$ phase and $\sigma$ phase were enhanced with the increase of tempering temperature, but the $\alpha$ phase diffraction peak intensity was in an opposite trend. Because of $\sigma$ phase formed by a eutectoid-type reaction of $\alpha \rightarrow \sigma+\gamma_{2}$, the higher tempering temperature not only increased the precipitation of $\sigma$ phase, but also decreased the amount of $\alpha$ phase.

Metallographic photos of the samples with different heat treatment procedures were taken to calculate the volume fraction of $\sigma$ phase, $\gamma$ phase and $\alpha$ phase by Image Pro-Plus software. Figure 6 shows that the volume fractions of all the phases followed a linear trend on the tempering temperature. The volume fraction of $\gamma$ phase increased slightly and $\sigma$ phase increased drastically with the increase of tempering temperature, while $\alpha$ phase decreased significantly since a eutectoid reaction of $\alpha \rightarrow \sigma+\gamma_{2}$ occurred during the solidification of molten liquid. The volume fraction of $\sigma$ phase was $2.7 \%$ and $\alpha$ phase was $50.4 \%$ when the tempering temperature was $720^{\circ} \mathrm{C}$. When the tempering temperature rose to $780{ }^{\circ} \mathrm{C}$, the volume fraction of $\sigma$ phase increased to $17.0 \%$ and $\alpha$ phase reduced to $34.4 \%$. There was no $\sigma$ phase precipitation when the sample was only solution treated at $1,060{ }^{\circ} \mathrm{C}$. The $\sigma$ phase precipitation curve is " $\mathrm{C}$ " shaped, and the precipitation temperature is between $600-950{ }^{\circ} \mathrm{C}{ }^{[23]}$. Calculated equilibrium phase diagram (Fig. 2) shows that solution temperature of $1,060{ }^{\circ} \mathrm{C}$ is not in the temperature range 


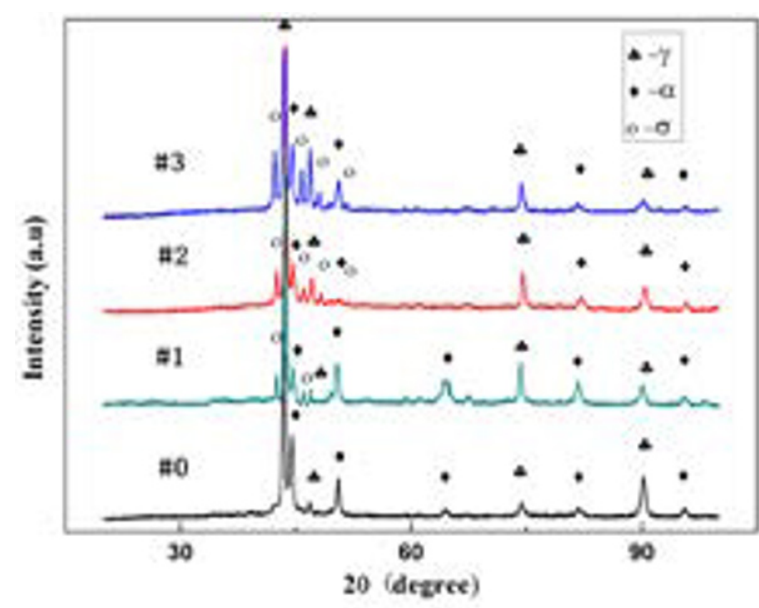

rig. 5: XKU patterns ot samples

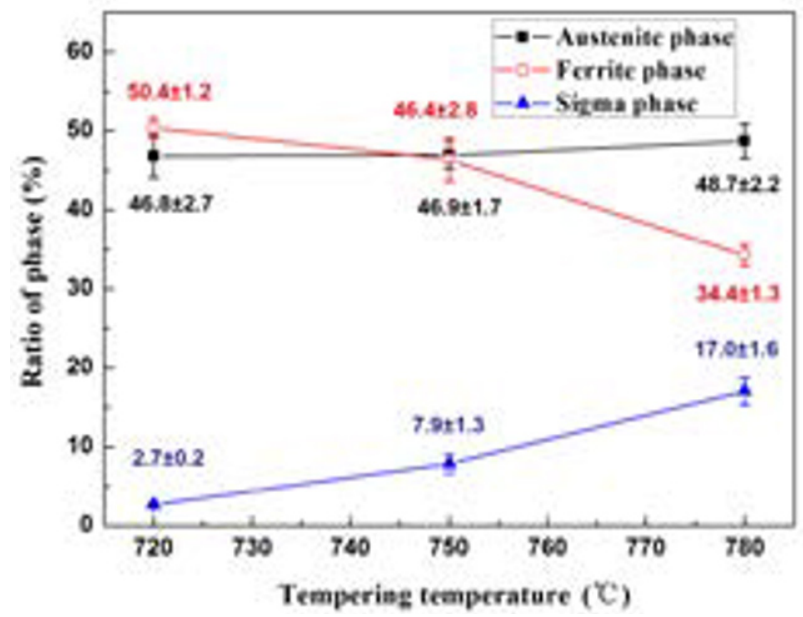

Fig. 6: Variation of volume fraction of phases for different tempering temperatures

of $\sigma$ phase precipitation. In addition, the water cooled process of solution treatment is very short, and it does not reach the incubation period of the $\sigma$ phase.

\subsection{Mechanical properties}

Figure 7 shows the Brinell hardness of samples tempered at different temperatures. Brinell hardness of samples increased significantly with an increasing tempering temperature, and it was $244.0 \mathrm{HB}$ when sample was only solution-treated at $1,060{ }^{\circ} \mathrm{C}$. However, it increased to $391.8 \mathrm{HB}$ when tempering of sample was conducted at $780{ }^{\circ} \mathrm{C}$ after solution treatment at $1,060^{\circ} \mathrm{C}$. Because $\sigma$ phase was a high hardness and brittle phase, it increased the hardness of the steel. Figure 8 shows micro-hardness of $\gamma, \alpha$ and $\sigma$ phases. The $\gamma$ phase was $282.3 \mathrm{HV}, \alpha$ phase was $301.1 \mathrm{HV}, \sigma$ phase reached 506.8 HV. Therefore, the precipitation of the $\sigma$ phase was the main reason for the significant increase of hardness in these samples.

Figure 9 shows the impact energy of samples at different tempering temperatures. The impact energy decreased with the increase of tempering temperature. The impact energy of the sample only solution treated at $1,060^{\circ} \mathrm{C}$ was $61.1 \mathrm{~J}$. It decreased to $1.5 \mathrm{~J}$ when tempering of the sample was conducted at $780{ }^{\circ} \mathrm{C}$ after solution treatment at $1,060{ }^{\circ} \mathrm{C}$ because a great deal of $\sigma$ brittle phase occurred at $780{ }^{\circ} \mathrm{C}$. Figure 10 shows the impact fracture

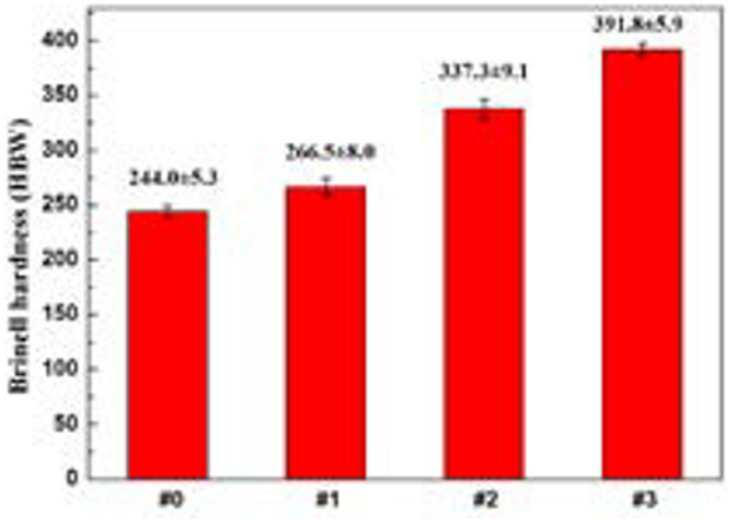

Fig. 7: Brinell hardness of samples

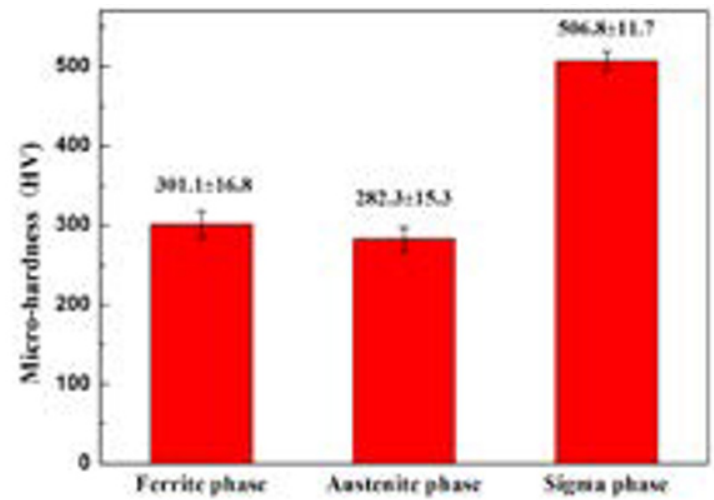

Fig. 8: Micro-hardness of ferrite, austenite and sigma phases

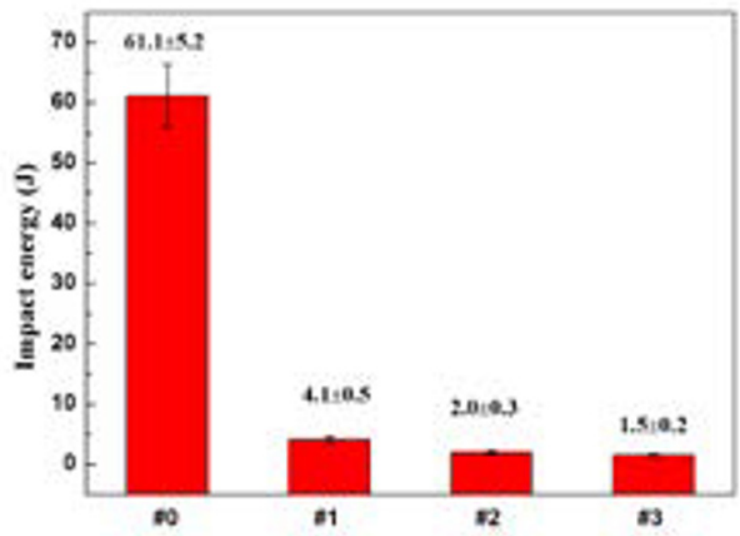

Fig. 9: Impact energy of samples

profile of the samples. There were a large number of dimples at the fracture surface [Fig. 10(a)] of the sample solution treated only at $1,060{ }^{\circ} \mathrm{C}$, and it belonged to toughness fracture. There only were a few dimples at the fracture surface which belonged to brittle fracture [Fig. 10(b)] when the sample was tempered at $720{ }^{\circ} \mathrm{C}$, and, especially at 750 and $780{ }^{\circ} \mathrm{C}$, there were few dimples [Fig. 10(c), (d)] .

\subsection{Corrosion resistance}

In order to study the effect of $\sigma$ phase on the corrosion resistance of $\mathrm{ZG} 0 \mathrm{Cr} 26 \mathrm{Ni} 5 \mathrm{Mo} 3 \mathrm{Cu} 3$, potentiodynamic polarization tests of samples under different tempering temperatures were conducted. Figure 11 shows the result of the potentiodynamic polarization tests. The overall polarization curves of the samples 

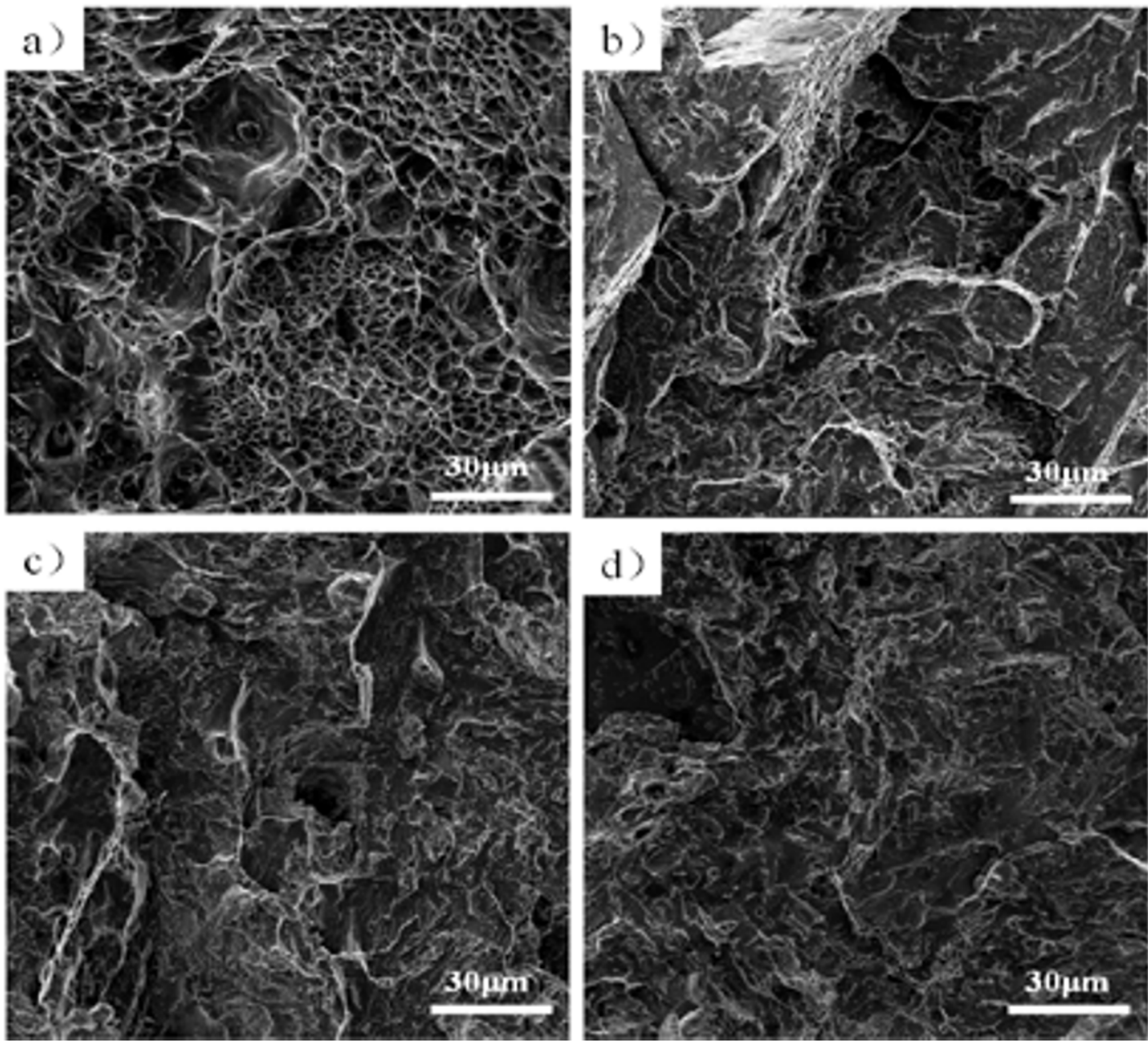

Fig. 10: SEM micrographs of fracture surface of samples: (a) \#0; (b) \#1; (c) \#2; d) \#3

after the different heat treatments were similar, and an obvious passivation zone occurred during the anodic polarization process. Due to the presence of $\mathrm{Cr}$, it quickly formed a passivation film on the surface of the sample when the corrosion took place. The reaction of oxygen depolarization occurred at the cathode (Equation 1), while the dissolution of the metallic matrix ( $\mathrm{Cr}$ and $\mathrm{Fe}$ ) happened at the anode. These reactions eventually led to the formation of $\mathrm{Cr}_{2} \mathrm{O}_{3}$ (Equation 2), $\mathrm{Fe}_{3} \mathrm{O}_{4}$ (Equation 5) and $\mathrm{Fe}_{2} \mathrm{O}_{3}$ (Equation 6):

$$
\begin{aligned}
& \mathrm{O}_{2}+\mathrm{H}_{2} \mathrm{O}+4 \mathrm{e}^{-} \rightarrow 4 \mathrm{OH}^{-} \\
& 2 \mathrm{Cr}+6 \mathrm{OH}^{-} \rightarrow \mathrm{Cr}_{2} \mathrm{O}_{3}+3 \mathrm{H}_{2} \mathrm{O}+6 \mathrm{e}^{-} \\
& \mathrm{Fe}+\mathrm{OH}^{-} \rightarrow \mathrm{FeOH}^{+}+2 \mathrm{e}^{-} \\
& \mathrm{FeOH}+\mathrm{OH}^{-} \rightarrow \mathrm{Fe}(\mathrm{OH})_{2} \\
& 3 \mathrm{Fe}(\mathrm{OH})_{2}+2 \mathrm{OH}^{-} \rightarrow \mathrm{Fe}_{3} \mathrm{O}_{4}+4 \mathrm{H}_{2} \mathrm{O}+2 \mathrm{e}^{-} \\
& 2 \mathrm{Fe}(\mathrm{OH})_{2}+2 \mathrm{OH}^{-} \rightarrow \mathrm{Fe}_{2} \mathrm{O}_{3}+3 \mathrm{H}_{2} \mathrm{O}+2 \mathrm{e}^{-}
\end{aligned}
$$

Table 3 shows the corrosion potential and corrosion current of the samples after different heat treatments by extrapolation. Compared with the sample that was only solution treated, the corrosion potential of the samples which were tempered after solution treatment reduced and the corrosion current increased. With the increase of tempering temperature, the corrosion

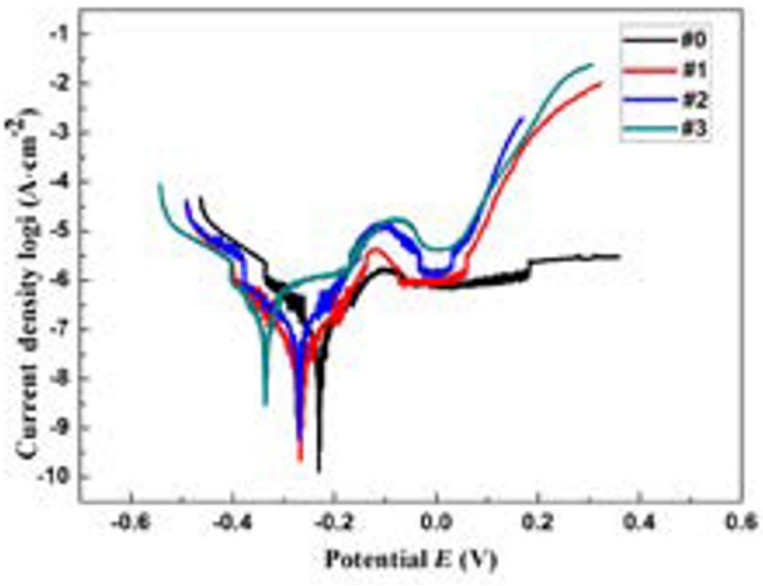

Fig. 11: Polarization curves of samples

Table 3: Corrosion potential and corrosion current of samples

$\begin{array}{ccc}\text { Samples } & \begin{array}{c}\text { Corrosion potential } \\ (\mathrm{mV})\end{array} & \begin{array}{c}\text { Corrosion current } \\ (\boldsymbol{\mu A})\end{array} \\ \# 0 & -230.9 & 0.05 \\ \# 1 & -263.6 & 0.05 \\ \# 2 & -270.9 & 0.07 \\ \# 3 & -335.5 & 0.31\end{array}$


potential of the samples decreased and the corrosion current increased. The corrosion resistance of the sample deteriorated. Because the precipitated $\sigma$ phase was rich in $\mathrm{Cr}$ and $\mathrm{Mo}$ at the grain boundary of ferrite-austenite phases and inside $\alpha$ phase, the adjacent zones become depleted of $\mathrm{Cr}$ and Mo. It caused deterioration of the corrosion resistance of the steels. The good corrosion resistance of duplex stainless steel is mainly related to the protective passivation film formed by $\mathrm{Cr}$ and $\mathrm{Mo}$ elements. When steel has low $\mathrm{Cr}$ and Mo zones, it will decrease the uniformity and densification of passivation film, thus the material is easily corroded. With the increase of the volume fraction of $\sigma$ phase, zones that were depleted of $\mathrm{Cr}$ and $\mathrm{Mo}$ increased, and the corrosion resistance of samples decreased.

\section{Conclusions}

(1) The $\sigma$ phase precipitated at the grain boundary of the ferrite-austenite phases and inside the $\alpha$ phase, when samples were tempered at 720,750 and $780{ }^{\circ} \mathrm{C}$, and no $\sigma$ phase was detected when the sample was only solution treated at 1,060 ${ }^{\circ} \mathrm{C}$. The volume fractions of $\sigma$ and $\gamma$ phases increased in the tempering temperature range of $720-780{ }^{\circ} \mathrm{C}$, whereas the volume fraction of $\alpha$ phase decreased with the increase of tempering temperature.

(2) Compared to the sample only solution treated at $1,060{ }^{\circ} \mathrm{C}$, the tempered samples had significantly increased hardness and decreased impact toughness for the samples tempered at 720 , 750 and $780{ }^{\circ} \mathrm{C}$ after solution treatment at $1,060^{\circ} \mathrm{C}$. The microhardness of the $\sigma$ phase was much higher than that of the $\alpha$ phase and $\gamma$ phase. As the volume fraction of $\sigma$ phase increased, the hardness of the sample increased, and impact toughness decreased.

(3) The precipitation of $\sigma$ phase led to $\mathrm{Cr}$ and Mo depletion in the surroundings. The corrosion resistance of the sample decreased. With the increase of the volume fraction of $\sigma$ phase, the corrosion resistance of samples decreased.

\section{References}

[1] Yang S M, Chen Y C, Chen C H, et al. Microstructural Characterization of $\delta / \gamma / \sigma / \mathrm{V}_{2} / X$ Phases in Silver-Doped 2205 Duplex Stainless Steel under $800{ }^{\circ} \mathrm{C}$ Aging. Journal of Alloys and Compounds, 2015, 633: 48-53.

[2] Lacerda J C D, Cândido L C and Godefroid L B. Effect of Volume Fraction of Phases and Precipitates on the Mechanical Behavior of UNS S31803 Duplex Stainless Steel. International Journal of Fatigue, 2015, 74(12): 81-87.

[3] Park $Y H$, Lee $Z H$. The effect of nitrogen and heat treatment on the microstructure and tensile properties of $25 \mathrm{Cr}-7 \mathrm{Ni}-1.5 \mathrm{Mo}-3 \mathrm{~W}-x \mathrm{~N}$ duplex stainless steel castings. Materials Science and Engineering A, 2001, 297(1-2): 78-84.

[4] Geng S, Sun J, Guo L, et al. Evolution of Microstructure and Corrosion Behavior in 2205 Duplex Stainless Steel Gta-Welding Joint. Journal of Manufacturing Processes, 2015, 19:32-37.

[5] Neessen F, Bandsma P and Smitweld L. Tankers - A composition in duplex stainless steels. Welding Innovation, 2001, 18: 3-8.

[6] Ma M, Ding H, Misra R D K, et al. A Study on Precipitation Kinetics of Sigma Phase in a Hot-Rolled Super Duplex Stainless Steel During Isothermal Aging Based on the Johnson-Mehl-Avrami Model. Ironmaking \& Steelmaking, 2016, 44(4): 311-318.

[7] Nilsson J O. Super duplex stainless steels. Metal Science Journal, 2014, 8(8): 685-700.

[8] Silva R, Baroni L F S, Silva M B R, et al. Effect of Thermal Aging at $475{ }^{\circ} \mathrm{C}$ on the Properties of Lean Duplex Stainless Steel 2101. Materials Characterization, 2016, 114: 211-217.

[9] Vijayalakshmi K, Muthupandi V and Jayachitra R. Influence of Heat Treatment on the Microstructure Ultrasonic Attenuation and Hardness of Saf 2205 Duplex Stainless Steel. Materials Science and Engineering A, 2011, 529(1): 447-451.

[10] Zhang Z, Jing H, Xu L, et al. Investigation on Microstructure Evolution and Properties of Duplex Stainless Steel Joint Multi-Pass Welded by Using Different Methods, Materials \& Design, 2016,109: 670-685.

[11] Breda M, Pellizzari M and Frigo M. $\sigma$-Phase in Lean Duplex Stainless Steel Sheets. Acta Metallurgica Sinica, 2015, 28(3): 331-337.

[12] Tahaei A, Perez A F M, Merlin M, et al. Effect of the Addition of Nickel Powder and Post Weld Heat Treatment on the Metallurgical and Mechanical Properties of the Welded UNS S32304 Duplex Stainless Steel. Soldag Insp, 2016, 21(2): 197-208.

[13] Silva E D M, Leite J P, Fialho W M L, et al. Induced Magnetic Field Used to Detect the Sigma Phase of a 2205 Duplex Stainless Steel. Journal of Nondestructive Evaluation, 2016, 35(2): 1-10.

[14] Santos D C D and Magnabosco R. Kinetic Study to Predict Sigma Phase Formation in Duplex Stainless Steels. Metallurgical and Materials Transactions A, 2016, 47(4): 1554-1565.

[15] Fargas G, Mestra A and Mateo A. Effect of Sigma Phase on the Wear Behavior of a Super Duplex Stainless Steel.Wear, 2013, 303(1-2): 584-590.

[16] Huallpa E A, Monlevade E F D, Campos M A, et al. Use of Magnetic Barkhausen Noise (MBN) to Follow up the Formation of Sigma Phase in Saf2205 (UNS S31803) Duplex Stainless Steel. Materials Research, 2016, 19(10): 8-16.

[17] García C, Martín F, Blanco Y, et al. Effect of ageing heat treatments on the microstructure and intergranular corrosion of powder metallurgy duplex stainless steels. Corrosion Science, 2010, 52(11): 3725-3737.

[18] Llorca-Isern N, López-Luque H, López-Jiménez I, et al. Identification of sigma and chi phases in duplex stainless steels. Materials Characterization, 2016, 112: 20-29.

[19] Wang Y Q, Han J, Wu H C, et al. Effect of Sigma Phase Precipitation on the Mechanical and Wear Properties of Z3CN20.09M Cast Duplex Stainless Steel. Nuclear Engineering and Design, 2013, 259: 1-7.

[20] Lee H W, Bae H S. Effect of Intermetallic Precipitation on the Properties of Multi Passed Duplex Stainless Steel Weldment. Korean Journal of Metals and Materials, 2014, 52: (8)631-636.

[21] Beraha E, Shpigler B. Color metallography. Metals Park: American Society for Metals, 1977.

[22] Maehara $Y$, Koike M, Fujino N, et al. Precipitation of $\sigma$ Phase in a 25Cr-7Ni-3Mo Duplex Phase Stainless Steel. ISIJ International, 1983, 23(3): 240-246.

[23] Maehara Y, Fujino N, Kunitake T. Effects of Plastic Deformation and Thermal History on $\sigma$ Phase Precipitation in Duplex Phase Stainless Steels. ISIJ International, 1983, 23(3): 247-255. 